\title{
Creating Transgenic shRNA Mice by Recombinase-Mediated Cassette Exchange
}

\author{
Prem K. Premsrirut, Lukas E. Dow, Youngkyu Park, Gregory J. Hannon, and Scott W. Lowe
}

RNA interference (RNAi) enables sequence-specific, experimentally induced silencing of virtually any gene by tapping into innate regulatory mechanisms that are conserved among most eukaryotes. The principles that enable transgenic RNAi in cell lines can also be used to create transgenic animals, which express short-hairpin RNAs (shRNAs) in a regulated or tissue-specific fashion. However, RNAi in transgenic animals is somewhat more challenging than RNAi in cultured cells. The activities of promoters that are commonly used for shRNA expression in cell culture can vary enormously in different tissues, and founder lines also typically vary in transgene expression due to the effects of their single integration sites. There are many ways to produce mice carrying shRNA transgenes and the method described here uses recombinase-mediated cassette exchange (RMCE). RMCE permits insertion of the shRNA transgene into a well-characterized locus that gives reproducible and predictable expression in each founder and enhances the probability of potent expression in many cell types. This procedure is more involved and complex than simple pronuclear injection, but if even a few shRNA mice are envisioned, for example, to probe the functions of several genes, the effort of setting up the processes outlined below are well worthwhile. Note that when creating a transgenic mouse, one should take care to use the most potent shRNA possible. As a rule of thumb, the sequence chosen should provide $>90 \%$ knockdown when introduced into cultured cells at single copy (e.g., on retroviral infection at a multiplicity of $\leq 0.3)$.

It is essential that you consult the appropriate Material Safety Data Sheets and your institution's Environmental Health and Safety Office for proper handling of equipment and hazardous material used in this protocol.

\section{Reagents}

$\beta$-Mercaptoethanol (100x) Add $75 \mathrm{~mL}$ of $\beta$-mercaptoethanol to $500 \mathrm{~mL}$ of PBS. Filter the mixture and aliquot $50 \mathrm{~mL}$ each to individual tubes. Store for up to several weeks at $4^{\circ} \mathrm{C}$.

DNA for electroporation

Doxycyline solution

EDTA

Embryonic stem (ES) cells

ES Cell Nucleofector Kit (Lonza DHPH1001)

ES-cell-tested fetal bovine serum (FBS; Stem Cell Technologies 6952)

Adapted from RNA: A Laboratory Manual by Donald C. Rio, Manuel Ares Jr, Gregory J. Hannon, and Timothy W. Nilsen. CSHL Press, Cold Spring Harbor, NY, USA, 2011.

(C) 2013 Cold Spring Harbor Laboratory Press

Cite this article as Cold Spring Harb Protoc; 2013; doi:10.1101/pdb.prot077057 
P.K. Premsrirut et al.

Feeder cells

Use mouse embryo fibroblasts (MEFs; immortalized and irradiated; see Step 5) or DR4 cells. Note that the feeders must be resistant to the antibiotic used for selection of modified ES cell clones, in this case hygromycin and neomycin. For the protocol presented here, DR4 cells, which are hygromycin, puromycin, neomycin, and 6thioguanine resistant, are used. These can be obtained in a ready-to-use form from Open Biosystems (MES3948).

Feeder medium

Combine $500 \mathrm{~mL}$ of knockout DMEM, $60 \mathrm{~mL}$ of ES-cell-tested FBS, and $6 \mathrm{~mL}$ of GPS solution. Store for up to several weeks at $4^{\circ} \mathrm{C}$.

Flp-e plasmid

Flp-In vector

Freezing medium

Combine $6 \mathrm{~mL}$ of M15 medium, $1 \mathrm{~mL}$ of DMSO, and $3 \mathrm{~mL}$ of FBS. This can be kept for up to $1 \mathrm{wk}$ at $4^{\circ} \mathrm{C}$. Do not store for longer than $1 \mathrm{wk}$ after it is made.

Gelatin solution $(0.1 \%)$

Geneticin (Life Technologies 10131-035)

GPS (glutamine/penicillin/streptomycin) solution

Dissolve $500 \mathrm{mg}$ of penicillin and $300 \mathrm{mg}$ of streptomycin in 100x glutamine solution and adjust the volume to $100 \mathrm{~mL}$. Filter through a $0.2-\mu \mathrm{m}$ filter unit. Aliquot ( $6 \mathrm{~mL}$ is a convenient size) and freeze at $-20^{\circ} \mathrm{C}$.

Hybrimax dimethysulfoxide (DMSO; Sigma-Aldrich D2650)

Hygromycin solution

Knockout Dulbecco's modified Eagle's medium (DMEM; Life Technologies 10829-018)

L-Glutamine (200 mM; 100×; Life Technologies 25030-081)

LIF (leukemia inhibitory factor) ESGRO (Millipore ESG1107)

M15 medium

Combine $500 \mathrm{~mL}$ of knockout DMEM, $90 \mathrm{~mL}$ of ES-cell-tested FBS, $6 \mathrm{~mL}$ of GPS solution, $6 \mathrm{~mL}$ of $\beta$-mercaptoethanol, and $60 \mathrm{~mL}$ of LIF. Store for up to several weeks at $4^{\circ} \mathrm{C}$.

M15 medium + hygromycin

Add $1.68 \mathrm{~mL}$ of hygromycin stock solution $(140 \mathrm{mg} / \mathrm{mL}$ ) to $600 \mathrm{~mL}$ of $\mathrm{M} 15$ medium. Store for up to several weeks at $4^{\circ} \mathrm{C}$.

miR-30-based shRNA (see Creating an miR30-Based shRNA Vector [Chang et al. 2013a])

Neomycin solution

Penicillin G (ICN 194537)

Phosphate-buffered saline (PBS)

QIAGEN Gentra Puregene DNA Kit

Streptomycin sulfate (Life Technologies 11860-038)

Trypsin-EDTA (0.25\%; Life Technologies 25200-056)

Trypsin-EDTA (0.5\%; Life Technologies 15400-054)

\section{Equipment}

Centrifuge (low speed)

$\mathrm{CO}_{2}$ incubator

Electroporation cuvettes

Electroporator or Amaxa nucleofector (single or 96-well model; Lonza)

Falcon tube $(15 \mathrm{~mL})$

Fluoresence microscope, FACS, or benchtop Guava instrument (Millipore)

$\gamma$-Irradiation source

Gene Pulser (Bio-Rad)

Hemocytometer or Coulter counter

Liquid nitrogen storage tank

Microscopes for viewing and picking ES cell clones 
P20 pipette (Ranin)

Plates (12 well, 24 well, 96 well, round bottomed)

Rocking platform

Tissue culture incubator

Tissue culture plates $(6-10 \mathrm{~cm})$

Tubes $(50 \mathrm{~mL}, 15 \mathrm{~mL})$

Water bath

\section{METHOD}

This is a long protocol, involving many individual steps, each of which must be executed precisely to ensure the ultimate successful creation of a transgenic animal. It is presumed that the investigator will have already created an appropriate miR-30-based shRNA (or used another scaffold) (see Creating an miR30-Based shRNA Vector [Chang et al. 2013a] and Packaging shRNA Retroviruses [Chang et al. 2013b]) and carefully tested the properties of the construct. It is also assumed that the laboratory is relatively proficient in embryonic stem (ES) cell culture. Careful culture of ES cells is essential for maintenance of pluripotency and therefore for the creation of mice with a germline derived from the engineered cells. The ES cells recommended in the following protocol are $F_{1}$ hybrids and are more robust than many ES cells, derived from pure backgrounds, that are often used for the creation of knockout mice by homologous recombination. For use in this protocol, shRNA inserts must be cloned into the Flp-In vector, shown in Figure 1, or a similarly constructed derivative (see Creating an miR30-Based shRNA Vector [Chang et al. 2013a]). DNA for RMCE should be of high quality, prepared using a large-scale preparation protocol such as CsCl purification or isolated using a QIAGEN-tip 100 or 500 (QIAGEN 12143 or 12165).

\section{Preparation of Gelatin-Coated ES Culture Plates}

These steps should be performed immediately before use.

1. Add $0.1 \%$ of gelatin solution directly to tissue culture plates at least $1 \mathrm{~h}$ before use. Use $6 \mathrm{~mL}$ for a 10 -cm plate, $2 \mathrm{~mL}$ for a 6 -cm plate, $1.5 \mathrm{~mL}$ per well for a six-well plate, and $0.5 \mathrm{~mL}$ per well for 24-well plate.
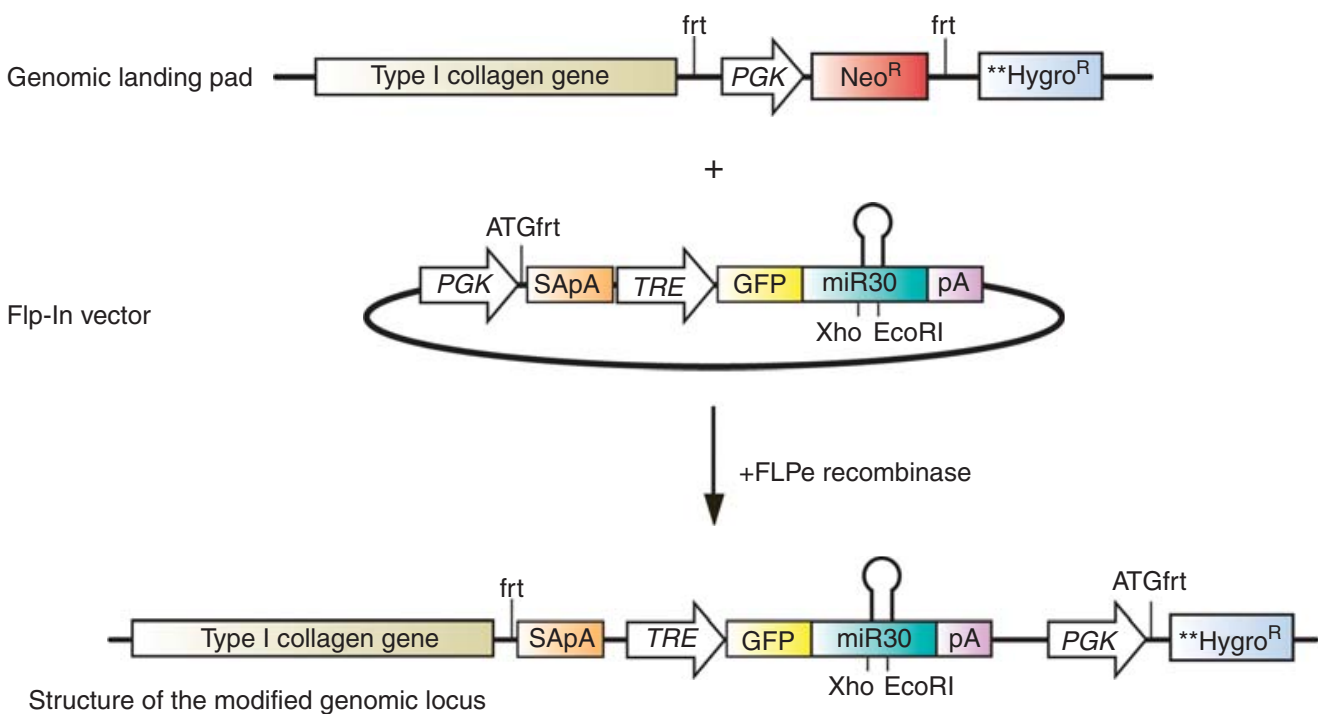

Structure of the modified genomic locus

FIGURE 1. Creating an RNAi mouse by RCME. (Upper panel) Representation of the genomic locus in KH2 ES cells that will receive the integrated shRNA vector. Key features are two frt sites that flank a neomycin/G418-resistance gene and a hygromycin-resistance gene that lacks both a promoter and a translation initiation site. (Middle panel) The integration vector, modified from Beard et al. (2006), in which a tetracycline-responsive promoter drives a miR-30-based shRNA cassette. This can be inserted into the landing pad via the action of FLP recombinase, supplied by the cotransfected FLP-e plasmid. Once integrated (lower panel), the G418-resistance cassette is lost, replaced by the tetracycline-responsive shRNA cassette. Additionally, the previously inactive hygromycin-resistance gene receives both a PGK promoter and an initiating ATG to permit its expression. 
P.K. Premsrirut et al.

\section{BOX 1. PREPARATION OF FEEDER CELLS}

1. Grow primary or immortalized MEF derivatives in feeder medium to confluency in a 15$\mathrm{cm}$ plate.

2. Add trypsin $(3 \mathrm{~mL})$ to the cells and incubate them for $3-5 \mathrm{~min}$ at $37^{\circ} \mathrm{C}$.

3. Add $10 \mathrm{~mL}$ of M15 medium and mix the cells by pipetting them up and down more than five times.

4. Transfer the cells in medium to a $50-\mathrm{mL}$ tube and expose them to $4300 \mathrm{rad}$ of $\gamma$ irradiation.

5. Centrifuge the cells at $1000 \mathrm{rpm}$ for $5 \mathrm{~min}$ at room temperature.

6. Resupend the irradiated cells at a concentration of $5 \times 10^{6}$ cells $/ \mathrm{mL}$ in freezing medium. Count the cells using a hemocytometer or Coulter counter.

It is wise to prepare large batches of feeder cells and bank them for future use. Plates can be prepared with feeders and kept in the $\mathrm{CO}_{2}$ incubator for up to 2-3 wk. Change the medium on feeders at least once a week.

2. Rock the plates to spread the solution evenly over the surface. Allow the plates to sit for 5-30 min at room temperature.

3. Immediately before use, aspirate the gelatin solution and then add tissue culture medium.

4. If the plates are not to be used immediately, keep them with the gelatin solution for up to several hours at room temperature.

\section{Plating of Irradiated Feeder Cells}

5. Culture ES cells on a layer of irradiated feeder cells.

These feeder cells are generally created from immortalized MEFs. Feeders ready for use can be purchased commercially or they can be created in the laboratory by treatment in a $\gamma$ irradiator or with a DNA-damaging agent (see Box 1).

6. Thaw a vial of DR4 feeder cells containing $\sim 7 \times 10^{6}$ to $8 \times 10^{6}$ cells.

About $0.9 \times 10^{6}$ to $1 \times 10^{6}$ feeders will be needed for a 10 -cm gelatin-coated plate. This amount can be scaled as needed for other culture vessels (according to their surface area).

7. Add $5 \mathrm{~mL}$ of feeder medium to the thawed cells and recover the feeder cells by centrifuging at $800-1000 \mathrm{~g}$ for $5 \mathrm{~min}$ at room temperature.

8. Aspirate the medium and suspend the cells in $80 \mathrm{~mL}$ of fresh feeder medium.

9. Aspirate the medium from a gelatin-coated $10-\mathrm{cm}$ plate (see Step 3).

10. Add $10 \mathrm{~mL}$ of the cell suspension to the gelatin-coated plate.

\section{Culture of ES Cells Before Electroporation}

KH2 ES cells are an $F_{1}$ hybrid line that has been engineered with an integration site at the Col1a locus (Beard et al. 2006). This site contains a Flp-recognition target (FRT) site and a hygromycin-selectable marker that lacks both a promoter and a translation initiation site. Cotransfection of $\mathrm{KH} 2$ cells with the shRNA homing cassette and a plasmid encoding Flp-e recombinase facilitates integration specifically into that site. This not only places the shRNA at a defined chromosomal locus but also reconstitutes the hygromycin marker, allowing positive selection for proper integration (see Fig. 1).

11. Thaw the KH2 ES cells from archival vials in liquid nitrogen.

12. Add the thawed cells to $5 \mathrm{~mL}$ of ES cell medium and recover them by centrifugation at $800-1000 \mathrm{~g}$ for $5 \mathrm{~min}$ at room temperature.

13. Plate the cells onto a 6- to $10-\mathrm{cm}$ plate coated with DR4 feeder cells. 
14. Culture the cells for at least $2 \mathrm{~d}$ before electroporation.

Because ES cells divide very quickly, care must be taken to maintain them in a healthy, proliferative state. This is essential for proper gene transfer and for maintaining potency. Split ES cells in routine culture once the cells are $70 \%-80 \%$ confluent. Always pass them by dividing 1:2-1:3. Always exchange medium on the cells a few hours before splitting, transfecting, or freezing. ES cells tend to turn their medium yellow over time. This is a sign that they are doing well in culture. In general, the plating density should be 4 million cells per 10-cm plate. Most importantly, change the medium daily on ES cells.

15. Exchange the medium $2 \mathrm{~h}$ before electroporation.

16. Trypsinize to recover the ES cells. Plate the mixture of ES cells and feeder cells on a gelatin-coated plate for $30 \mathrm{~min}$ before electroporation. The feeders will attach to the plate, whereas the ES cells will not.

17. Recover the medium containing the ES cells and depleted of feeder cells. Determine the concentration of ES cells using a hemocytometer or Coulter counter.

\section{Introduction of Transgenes into KH2 ES Cells}

Plasmids are generally introduced into ES cells by electroporation. The following section contains a standard method that can be used for integration of RMCE cassettes. Although this will work well, nucleofection using an Amaxa nucleofection instrument (Lonza) is more efficient and more amenable for scaling up. This instrument allows 96 constructs to be easily introduced in one session into KH2 ES cells. If using the Amaxa Nucleofector, follow the manufacturer's instructions (using the ES Cell Nucleofector Kit, Lonza DHPH1001), but use $6 \times 10^{4}$ cells, $5 \mu \mathrm{g}$ of the Flp-In vector, and $2.5 \mu \mathrm{g}$ of the Flp-e plasmid (Beard et al. 2006). The following procedure uses the Bio-Rad Gene Pulser, but other electroporation devices can also be adapted to perform similarly.

18. Prepare one 6-cm plate per construct for ES cell culture (with gelatin and feeder cells).

19. For each electroporation, mix $50 \mathrm{mg}$ of Flp-In vector (containing the shRNA of interest) with 25 $\mu \mathrm{g}$ of Flp-e plasmid in a $15-\mathrm{mL}$ tube.

20. Harvest healthy $\mathrm{KH} 2$ cells for electroporation in $1 \mathrm{~mL}$ of trypsin.

Generally, one $10-\mathrm{cm}$ plate will yield $2 \times 10^{7}$ cells, which is sufficient for three to four different electroporations.

21. Suspend cells with $10 \mathrm{~mL}$ of complete M15 medium.

Usually, $\sim 5 \mathrm{~min}$ at $37^{\circ} \mathrm{C}$ in trypsin will be sufficient to detach the ES cells before suspension.

22. Transfer the cells to a $15-\mathrm{mL}$ tube and collect the cells by centrifugation at $800-1000 \mathrm{~g}$ for $5 \mathrm{~min}$ at room temperature.

23. Suspend the cells thoroughly in $10 \mathrm{~mL}$ of PBS and recover them again by centrifugation at $800-1000 \mathrm{~g}$ for $5 \mathrm{~min}$ at room temperature.

24. Suspend the cells in PBS at $\sim 5 \times 10^{6}$ cells per $900 \mu \mathrm{L}$.

25. Add $900 \mu \mathrm{L}$ of $\mathrm{KH} 2$ cells to each tube containing DNA and mix by gently pipetting.

Be sure to use high-quality DNA for electroporation. It is suggested that the DNA be precipitated with ethanol twice and pellets washed well with $70 \%$ ethanol. Dissolve DNA at least to a concentration of above $1.5 \mu \mathrm{g} / \mu \mathrm{L}$. Run the DNA on a gel to make sure that there is no genomic DNA or RNA contamination. Store plasmids frozen at $-20^{\circ} \mathrm{C}$.

26. Transfer the cells to electroporation cuvettes (400-mm gap) at room temperature.

27. Pulse the cells twice at $125 \mu \mathrm{F}$ (capacitance) and $400 \mathrm{~V}$. If using one pulse, use $500 \mu \mathrm{F}$ and 240 V. Two pulses are recommended. To prevent arcing, be sure to thoroughly wipe the cuvette before placing it in the electroporator. The time constant should be between 1.0 and 1.7, and ideally 1.6.

28. Allow cells to remain in the electroporation cuvette for $15 \mathrm{~min}$ at room temperature.

29. Change the medium in the prepared 6-cm plates from Step 18, replacing it with $3 \mathrm{~mL}$ of complete M15 medium. 
P.K. Premsrirut et al.

30. Transfer the cells to the 6 -cm plate.

31. After $2 \mathrm{~d}$, proceed with hygromycin selection.

\section{Selection of ES Cell Clones Containing Properly Integrated shRNA Cassettes}

Once DNA constructs have been introduced into cells, those clones that arise from cells with the proper modification must be selected and isolated as clonal lines. After electroporation, cells will have been plated on feeders in nonselective M15 medium, and they should be left this way for $24 \mathrm{~h}$.

32. At $24 \mathrm{~h}$ postelectroporation or nucleofection, exchange medium for M15 + hygromycin (140 $\mu \mathrm{g} /$ $\mathrm{mL})$. Be sure to exchange this medium daily during selection.

33. Culture cells in M15 + hygromycin medium for 10-12 d, at which point the majority of ES cells will have died and a few discrete colonies should be easily visible.

Although the number of colonies will depend on the efficiency with which DNA was introduced, dozens to hundreds are expected for a 10-cm plate. Positive clones become visible usually from 9 to $10 \mathrm{~d}$ posthygromycin treatment. Pick the clones at days 10-12. Do not pick clones if they become visible only after $14 \mathrm{~d}$ of hygromycin treatment. They usually turn out to be incorrect.

34. Most hygromycin-resistant colonies contain a correctly integrated cassette, and thus only a few (in this case, four to six are recommended) need to be tested further for their integrity. Collect colonies while viewing under a microscope, aspirating them with a P20 pipette (e.g., Ranin) set to $7 \mu \mathrm{L}$.

35. Transfer each of the picked colonies, which are aggregates, to a well of a 96-well (roundbottomed) plate containing $25 \mu \mathrm{L}$ of PBS/trypsin/EDTA.

36. Incubate the cells at $37^{\circ} \mathrm{C}$ until they are dispersed.

37. Transfer the dispersed cells, representing each colony, to a well of a 24-well plate prepared with gelatin and feeder cells.

38. Culture the cells in M15 + hygromycin medium, with daily medium changes, until the cells become confluent.

39. Once confluent, recover the cells by treatment with trypsin to a total volume of $200 \mu \mathrm{L}$.

40. Add $300 \mu \mathrm{L}$ of M15 medium and aliquot the cells as follows:

i. For each clone, place $5 \mu \mathrm{L}$ of cells into each of two wells of a 96-well plate prepared with gelatin and feeders.

ii. This will be used to test for neomycin resistance (see Testing Neomycin Sensitivity, below). Two wells of a prepared 24-well plate should receive $30 \mu \mathrm{L}$ of cells for testing shRNA expression (see Testing for shRNA Expression, below). Both plates should also contain at least two wells of plated parental $\mathrm{KH} 2$ cells.

iii. Transfer the remaining cells to a prepared 6-cm plate, from which they should be expanded and archived by freezing in liquid nitrogen.

Testing Neomycin Sensitivity

The proper insertion of the shRNA-resistance cassette replaces a neomycin-resistance gene. Therefore, although parental KH2 cells are neomycin resistant, their properly engineered progeny should be sensitive.

41. On the day following plating, add neomycin to a final concentration of $140 \mu \mathrm{g} / \mathrm{mL}$ to one of the two wells representing each clone and to one of the two KH2 wells.

42. Incubate the plates for $4-5 \mathrm{~d}$ at $37^{\circ} \mathrm{C}$.

43. Score neomycin sensitivity visually. Cells with the correct integrations should be killed by neomycin treatment. 
Testing for shRNA Expression

KH2 cells have a tetracycline trans-activator (tet-on) integrated at the ROSA-26 locus, and the shRNA in Flp-In is under the control of the tet-CMV minimal promoter. Therefore, the shRNA can be induced by an activator, such as tetracycline or doxycycline. The shRNA resides within the 3' UTR of GFP, and as a result, the ability of doxycycline to induce the linked GFP reporter serves as a proxy for the ability to induce expression of the shRNA.

44. At the time of plating, or up to $1 \mathrm{~d}$ thereafter, add doxycycline to a final concentration of $1 \mu \mathrm{g} / \mathrm{mL}$ to one of the two wells containing each clone and to one of the two $\mathrm{KH} 2$ parental wells.

45. After $2 \mathrm{~d}$ of exposure to the inducing agent, score for GFP expression.

This can be done in any of several ways. The simplest is to view the cells on an appropriate fluorescence microscope. However, it is difficult to be quantitative using this approach. A better method is to analyze the cells for GFP fluorescence by FACS or using a benchtop instrument such as a Guava flow cytometer (Millipore).

Validation of Clones and Preparation of Frozen Stocks

Clones that have strong GFP induction and that display neomycin sensitivity should be tested by Southern blotting (see Validation of Clones by Southern Blotting, below) for proper integration and can be tested by northern blotting or quantitative PCR for induction of the shRNA (although this is optional).

46. About $4-5 \mathrm{~d}$ after plating, clones should reach $\sim 80 \%$ confluency on the 6 -cm dishes. These clones are now ready for storage and further validation. Begin by recovering cells using $600 \mu \mathrm{L}$ of trypsin/EDTA with an incubation time of $5-10 \mathrm{~min}$ at $37^{\circ} \mathrm{C}$.

47. Add $3 \mathrm{~mL}$ of M15 medium and transfer the cells to a 15-mL Falcon tube.

48. Remove $100 \mu \mathrm{L}$ of cells and plate them in a gelatin-coated 12 -well plate for isolation of genomic DNA.

49. Recover the cells for archiving by centrifugation at $800-1000 \mathrm{~g}$ for $5 \mathrm{~min}$ at room temperature.

50. Aspirate the medium and suspend the cells in $1 \mathrm{~mL}$ of ice-cold freezing medium.

51. Divide the cells among three vials, label the vials, and place them overnight at $-80^{\circ} \mathrm{C}$ before transfer to liquid nitrogen storage the next day.

Validation of Clones by Southern Blotting

This approach allows correct and single-copy transgene integration to be verified.

52. Purify genomic DNAs using the QIAGEN Gentra Puregene DNA Kit or through any other genomic DNA preparation method suitable for Southern blotting. To verify correct integration, digest genomic DNAs with SpeI.

Using a ColA1 region probe (see below), a band of $6 \mathrm{~kb}$, corresponding to the wild-type allele, and a band of $4 \mathrm{~kb}$, corresponding to the correctly modified allele, should be detected. Genomic DNA digested with EcoRI can be used to verify single-site integration, using a fragment of GFP as a probe (see below). Positive clones with a single-copy integration produce a band of $4 \mathrm{~kb}$. Bands of other sizes indicate multiple integrations.

ColA1 Probe

GACCTGAGGCCTGGGAGGTGTTGCCCATGGATCCTGGGAGGTTCATGAGCCCT CAAAGGGATTCAAGCAGCAGAAACAGGGACTGAGACATGGAGGACCAGGTTGCTC CTTGGTCACACATGGAGGGGTAGCTGGCCTCTCCCCACCTCTAGCCCAAAGAAAC CATAATTTAGTATAGAAGGGGCCTTCTAATGCTGGGGTGTCACAAGGAGGATGA GAATTTCTTGGGTCACCCTTGATCTCACCAGAGAGAGGTGCCCAGCCCTCAAG GAACTCTCCCCGGGGGATCTTAGAGAGCTGTGGTGGAACTTCCGGGGTGTCACCA GAAAGGACAGGACCCCACATCACAGAGGTGCCCGGGACGATAGCATGCTGGCTCG GTACAGGGAGCCCGTGGAATTGTTCCCCCСTTCTTCCTGCCСCСTTCTTTCCTTTTC

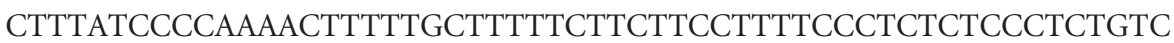
CATCTGAGAACCTGAGGCCCTAGAGGGATGGTAACTAATTGTCCCCCACATCTCAGA GAATGGGGACGGTGACATAGTAGAAGGCCCGAGAATCCAGCAGGCAGAAGTCTGGGGT 
P.K. Premsrirut et al.

\author{
GAACCAGACAGTAGACATAAGGACACAGATGACCCCTTTCACTCGGGGAGACAGGTCT \\ CAAATTTGAAAGGAAGGAACAGGCCATTTGTAGCTTCCCTCTCTTGTGCTACCAGTC \\ TACTGTGGCACCCATAGGACACGTTCATATGGTCACGGAGTATCCAAGACTATTAATGATG \\ GCCTTTAATAATTTATTATTACACTTTGCATGAGGACAACGTGAAAGGAAAATTTAT
}

GFP Probe (Entire GFP-Coding Sequence)

ATGGTGAGCAAGGGCGAGGAGCTGTTCACCGGGGTGGTGCCCATCCTGGTCGAGCTG GACGGCGACGTAAACGGCCACAAGTTCAGCGTGTCCGGCGAGGGCGAGGGCGATGC CACCTACGGCAAGCTGACCCTGAAGTTCATCTGCACCACCGGCAAGCTGCCCGTGCC CTGGCCCACCCTCGTGACCACCCTGACCTACGGCGTGCAGTGCTTCAGCCGCTACCCC GACCACATGAAGCAGCACGACT TCT TCAAGTCCGCCATGCCCGAAGGC TACGTCCAGGAGCGCACCATCTTCTTCAAGGACGACGGCAACTACAAGACCCGCGCC GAGGTGAAGTTCGAGGGCGACACCCTGGTGAACCGCATCGAGCTGAAGGGCATC GACTTCAAGGAGGACGGCAACATCCTGGGGCACAAGCTGGAGTACAACTACAACAGCCA CAACGTCTATATCATGGCCGACAAGCAGAAGAACGGCATCAAGGTGAACTTCAAGATC CGCCACAACATCGAGGACGGCAGCGTGCAGCTCGCCGACCACTACCAGCAGAACACCC CCATCGGCGACGGCCCCGTGCTGCTGCCCGACAACCACTACCTGAGCACCCAGTCCGC CCTGAGCAAAGACCCCAACGAGAAGCGCGATCACATGGTCCTGCTGGAGTTCGTGAC CGCCGCCGGGATCACTCTCGGCATGGACGAGCTGTACAAGTAATGA

\title{
Creation of Transgenic Mice
}

This is a very long procedure. Therefore, it is a good idea to resequence the genomically integrated shRNA sequence before making mice.

53. At this stage, use the cells to analyze the consequences of suppressing gene expression in the ES cells themselves or in derivatives of the ES cells, differentiated in vitro. However, the ultimate goal is to produce a mouse in which expression can be suppressed in tissues. This is generally accomplished by delivery of the ES cells to a core facility or company that will create the mice. Virtually all institutions have facilities capable of generating mice by blastocyst injection or by production of aggregation chimeras. In this case, the investigator must screen chimeric founders for those that transmit the shRNA allele through the germline. However, $\mathrm{KH} 2$ are robust $\mathrm{F}_{1}$ hybrid ES cells that can be used in tetraploid complementation to create mice wholly derived from the engineered cells. For institutions with this capability, this is by far the preferred route toward lines of shRNA-expressing animals.

\section{REFERENCES}

Beard C, Hochedlinger K, Plath K, Wutz A, Jaenisch R. 2006. Efficient method to generate single-copy transgenic mice by site-specific integration in embryonic stem cells. Genesis 44: 23-28.

Chang K, Marran K, Valentine A, Hannon GJ. 2013a. Creating an miR30based shRNA vector. Cold Spring Harb Protoc doi: 10.1101/pdb. prot075853.
Chang K, Marran K, Valentine A, Hannon GJ. 2013b. Packaging shRNA retroviruses. Cold Spring Harb Protoc doi: 10.1101/pdb. prot076448. 


\section{Creating Transgenic shRNA Mice by Recombinase-Mediated Cassette Exchange}

Prem K. Premsrirut, Lukas E. Dow, Youngkyu Park, Gregory J. Hannon and Scott W. Lowe

Cold Spring Harb Protoc; doi: 10.1101/pdb.prot077057

\begin{tabular}{rc}
$\begin{array}{r}\text { Email Alerting } \\
\text { Service }\end{array}$ & Receive free email alerts when new articles cite this article - click here. \\
\hline $\begin{array}{c}\text { Subject } \\
\text { Categories }\end{array}$ & Browse articles on similar topics from Cold Spring Harbor Protocols. \\
& DNA Delivery/Gene Transfer (344 articles) \\
& Mouse (437 articles) \\
& RNA (317 articles) \\
RNA Interference (RNAi)/siRNA (123 articles) & RNA, general (269 articles) \\
& Transgenic Mice (139 articles) \\
\hline
\end{tabular}

